\title{
Correspondence
}

\section{The correlation between mental disorders and terrorism is weak}

Hurlow et al ${ }^{1}$ contradict the assertion that severe mental illness does not have a significant role 'overall in the area of terrorism'. The authors state that there is evidence for mental illness in cases of lone-actor terrorism, suggesting that these cases are more likely to come to the attention of psychiatrists.

I strongly disagree with the authors. Although there are several psychological factors contributing to radicalisation, experts in terrorism studies agree that those who commit acts of terrorism 'are not mentally disturbed'.

There is little consensus in the literature regarding the importance of mental illness in lone-actor terrorism. However, the evidence suggests that mental illness is not a key factor contributing to acts of violence in these cases. ${ }^{3}$ It is therefore erroneous to insinuate that psychiatrists have a role in identifying these individuals. It is also highly questionable whether a 'future potential Breivik' would - or could - be identified by psychiatrists. In the case of Breivik, the forensic psychiatric evaluation concluded that although he has narcissistic personality disorder, he was not affected by a serious mental disorder when committing the act of terrorism, nor at the time of the evaluation.

The role of individual preventive interventions is limited in preventing relapse in regular criminality ${ }^{4}$ and remains highly controversial with regards to terrorism. ${ }^{5}$ The question of terrorism and mental health is extremely relevant and important, and warrants further study. However, the evidence to date shows a weak correlation between mental disorders and terrorist acts.

Ardavan Khoshnood, Resident in Emergency Medicine, Lund University, Skane University Hospital, Department of Clinical Sciences Lund, Emergency and Internal Medicine; MSc Criminology, Department of Criminology, Malmö University; BSc Intelligence Analysis, Lund University, Lund, Sweden; email: ardavan.khoshnood@med.lu.se

1 Hurlow J, Wilson S, James DV. Protesting loudly about Prevent is popular but is it informed and sensible? BJPsych Bull 2016; 40: 162-3.

2 Alonso R, Björgo T, Della Porta D, Coolsaet R, Khosrokhavar F, Lohelker R, et al. Radicalisation Processes Leading to Acts of Terrorism. A concise report prepared by the European Commission's Expert Group on Violent Radicalisation. Submitted to the European Commission on 15 May 2008.

3 Danzell OE, Maisonet Montañez LM. Understanding the lone wolf terror phenomena: assessing current profiles. Behavioral Sciences of Terrorism and Political Aggression 2016; 8: 135-59.
4 Khoshnood A, Väfors Fritz M. Offender characteristics: a study of 23 violent offenders in Sweden. Deviant Behavior 2016. DOI: 10.1080/ 01639625.2016.1196957.

5 Ranstorp M. Introduction: Mapping Terrorism Research. In Mapping Terrorism Research: State of the art, gaps and future direction (ed M Ranstorp). Routledge, 2007.

doi: $10.1192 / p b .41 .1 .56$

\section{Epistemic injustice or safety first?}

Crichton et al ${ }^{1}$ discussed the problem of testimonial epistemic injustice that has been historically prevalent and overlooked in both physical and mental healthcare settings. However, in the third example, the notion of epistemic injustice in the patient's compulsory detention is not clear. The patient was admitted after standing near the edge of a cliff for more than an hour, but his community psychiatric nurse argued the tribunal hearing that this man had had suicidal thoughts for several years and should never have been placed on a section.

In this case, the argument to keep the patient under section was made in light of apparent risks, without the background knowledge subsequently provided by the care coordinator. This is not the same as epistemic injustice, where the patient is not believed because of prejudice.

The admitting team's decision to detain under Section 2 does not appear to be secondary to epistemic injustice but rather a clinical decision following assessment of risk during a crisis presentation. These decisions often have to be made when there is limited time available, when one cannot contact the community psychiatric nurse and when one does not have access to a detailed written care plan. In such situations, the patient's safety is of overriding importance.

In our opinion this case represents epistemic contextualism - whereby one requires more certainty if the stakes are high rather than epistemic injustice per se. ${ }^{2}$

Manhal M. Zarroug, Higher Trainee in Psychiatry (ST5), email: Manhal.Zarroug@swlstg-tr.nhs.uk; Dieneke Hubbeling, Consultant Psychiatrist, and Robert Bertram, Associate Specialist (Psychiatry), South West London and St George's NHS Trust London, UK.

1 Crichton P, Carel H, Kidd IJ. Epistemic injustice in psychiatry. BJPsych Bull 2016, in press; published online ahead of print 25 August $2016-$ DOI: 10.1192/pb.bp.115.050682.

2 Cohen S. Contextualism, skepticism and the structure of reasons. Philos Perspect 1999; 13: 57-89.

doi: $10.1192 / p b .41 .1 .56 a$

\section{Correction}

Psychiatrists' use of psychological formulation. BJPsych Bulletin 2016; 40: 349. The declaration of interest was incorrect in the print version of this article. This should read: 'A.S., on behalf of the Medical Psychotherapy Faculty Executive Committee, was the lead author of Using Formulation in General
Psychiatric Care: Good Practice (Occasional Paper OP103, Royal College of Psychiatrists, 2017)'. The online version has been corrected post-publication.

doi: $10.1192 / \mathrm{pb} .41 .1 .56 \mathrm{~b}$ 